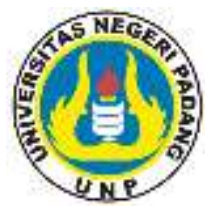

\title{
PENGARUH MEDIA KARTU KUARTET TERHADAP PENGUASAAN HIRAGANA SISWA KELAS X SMAN 6 PADANG
}

\author{
Afriyona Marta ${ }^{1}$, Nova Yulia ${ }^{2}$ \\ Prodi Pendidikan Bahasa Jepang, Fakultas Bahasa dan Seni, Universitas Negeri Padang \\ Prodi Pendidikan Bahasa Jepang, Fakultas Bahasa dan Seni, Universitas Negeri Padang \\ Email Penulis :afriyonamarta02@gmail.com
}

\section{Sejarah Artikel \\ Submit :2019-07-18 \\ Diterima : 2019-08-19}

Diterbitkan : 2019-08-30

\section{Kata Kunci:}

Hiragana, Media,quartet card

\begin{abstract}
Abstrak
Learning process of japanese in Indonesia still often encounter someproblems in learning letters. The use of different letters is one of the factors that cause the learners have difficulty to learn Japanese. Because of there are principles that are not fulfilled, namely the use of media and the methods or techniques used are not appropriate. Based on what the researcher observed when doing educational field practice (PLK) at SMAN 6 Padang and interviewed that researcher did with students, it shows that the lack of interest and ability of students to learn hiragana. So that the achievement of learning goals is not optimal. Therefore, certain media are needed to facilitate in mastering and to increase students' interest in learning hiragana. The use of quartet card media is possibly to resolve the problems. The purpose of this study is to find out how the effects of quartet card media on hiragana mastery of class $\mathrm{X}$ students of SMAN 6 Padang. This study uses quasi-experimental research with posttest only control group design. While the sampling technique uses purposive sampling technique. The sample in this study is the students of class X MIPA 1 and X MIPA 5 which amounts of 69 people. The result of data analysis, obtained t count with table significant level $0.05 \%$ is 2.00 with degrees of freedom $\mathrm{dk}=\mathrm{n} 1+\mathrm{n} 2-2$. It means that $t$ count $>t$ table $(3.41>2.00)$. Therefore, the hypothesis is accepted, because $t$ count $>t$ table.
\end{abstract}

\section{PENDAHULUAN}

Bahasa merupakan alat dalam penyampaian ide, gagasan dan pikiran. Seperti halnya Bahasa asing di Indonesia. Selain Bahasa Indonesia, pelajar Sekolah Menengah Atas (SMA) juga mempelajari beberapa Bahasa asing yang di antaranya adalah Bahasa Inggris, Arab, Jerman, Mandarin, dan Jepang. Dalam mempelajari Bahasa Jepang, huruf merupakan pelajaran yang paling mendasar yang nantinya digunakan untuk menuliskan kosakata, pola kalimat, dan materi lainnya. Dalam Bahasa Jepang, terdapat empat jenis huruf, yaitu hiragana, katakana, kanji, dan romaji. Menurut (Rahmi, Ulfia 2016 : 5) dalam mempelajari bahasa Jepang 
mempelajari huruf hiragana, katakana dan kanji merupakan hal yang tidak dapat dihindari. Hal ini sesuai dengan pendapat Dai Hayashi pada bukunya yang berjudul Nihongo Kyouiku Handobukku dalam (Hayashi, 1994, hlm.59) yang mengatakan:

日本語を多少とも体系的に学ぼうとする者は、文字 (平仮 名 片仮名 漢字) の学習を避けて通ることはできない。

Nihongo o taikeiteki ni manabou to suru mono wa, moji ( Hiragana, Katakana, Kanji) no gakusyuu o sakete tooru kota wa dekinai

Setiap pembelajar yang akan mempelajari bahasa Jepang secara sistem mereka tidak bisa menghindari pembelajaran hiragana, katakana dan kanji

Menurut Yuana (2012:10) hiragana adalah huruf yang digunakan untuk menuliskan kosakata yang berasal dari Jepang sendiri. Sedangkan katakana adalah huruf yang digunakan untuk menuliskan kosakata yang berasal dari serapan Bahasa asing (baik dari Bahasa Inggris, Jerman, Indonesia, Spanyol, dan Prancis). Selanjutnya, kanji adalah huruf yang awalnya diadopsi dari Cina kemudian dimodifikasi dan disesuaikan dengan kebutuhan Jepang dan akhirnya saat ini digunakan untuk menuliskan kosakata dalam Bahasa Jepang. Romaji adalah huruf yang sebenarnya berasal dari alphabet, digunakan untuk menuliskan kosakata atau kalimat dalam bahasa Jepang dengan tujuan untuk mempermudah pembelajar Bahasa Jepang.

Penggunaan huruf yang berbeda menjadi salah satu faktor yang menyebabkan pembelajar Bahasa Jepang merasa kesulitan dalam mempelajari Bahasa Jepang. Hal ini juga diungkapkan oleh Prayoga, dkk (2015:622) yang menyatakan bahwa hal yang paling penting dalam mempelajari bahasa Jepang yaitu mengenal baik huruf Katakana dan Hiragana. Proses pembelajaran Bahasa Jepang di Indonesia masih sering menemui beberapa kendala pada hal tersebut. Hal ini senada dengan pernyataan Sutedi (2011:41) yang menyatakan dalam mempelajari huruf Bahasa Jepang, masalah yang biasa dialami oleh pembelajar pemula tingkat dasar yaitu, ketika mempelajari hiragana pelajar sering terkecoh dengan bentuk hiragana yang hampir mirip, seperti: あ (a) dan お (o), わ(wa), ね (ne), dan れ (re), ぬ (nu) dan め (me), は (ha) danほ (ho), た (ta) dan な (na), さ (sa) danき (ki), る (ru) dan ろ (ro). Banyaknya jumlah hiragana juga sering kali menjadi hambatan pelajar dalam penguasaan hiragana, mengingat terdapat empat puluh enam huruf dasar hiragana, tiga puluh dua huruf hiragana yang memakai dakuten $\left.\Gamma^{*}\right\rfloor$, delapan huruf hiragana yang memakai handakuten $\left.\Gamma^{\circ}\right\rfloor$, dan sebanyak dua puluh satu konsonan ganda yang memakai ya/yu/yo kecil 「きや/きゅう/きょ」, jadi huruf hiragana yang harus dikuasai oleh pelajar tingkat pemula menjadi 107 huruf.

Sejalan dengan itu, menurut Puspitasari (dalam Adriyanto, Refnaldi, dan Yulia 2018:2) mengatakan bahwa dalam proses pembelajaran bahasa Jepang khususnya hiragana sering kali siswa mengalami kesulitan. Kesulitan-kesulitan tersebut yaitu dalam mengingat hiragana, kesulitan membaca dan mengucapkan, kesulitan membedakan, dan kesulitan menulis dengan urutan yang benar. Kesulitankesulitan tersebut muncul karena dikarenakan hiragana mempunyai jumlah 46 huruf mulai dari あ(a) sampai $ん(n)$ dan aturan penulisan yang banyak, sehingga cenderung sulit dikuasai. 
Berdasarkan dengan apa yang penulis amati pada saat melaksanakan praktik lapangan kependidikan (PLK) di SMAN 6 Padang serta wawancara yang penulis lakukan dengan siswa, menunjukkan bahwa masih rendahnya minat dan kemampuan siswa dalam mempelajari hiragana. Secara umum, siswa mengalami kesulitan dalam mengingat dan menuliskan hiragana dengan benar, disebabkan penguasaan dari hiragana siswa yang terbatas dan juga dilihat dari hasil belajar beberapa ulangan harian tentang penguasaan hiragana dari 36 siswa hanya 25\% yang memenuhi Kriteria Ketuntasan Minimal (KKM 75). Permasalahan ini tentunya juga sangat berkaitan dengan keaktifan siswa dalam berlatih.

Mengenai adanya beberapa asumsi mengapa pembelajaran hiragana terasa begitu sulit untuk diingat siswa yaitu: (1) Kurangnya media pembelajaran yang mampu menarik minat siswa. (2) Kurangnya ketertarikan siswa terhadap pembelajaran hiragana yang monoton dan tidak variatif. (3) Bentuk dari Hiragana yang sangat berbeda dengan alphabet membuat siswa kesulitan menghafal.

Melihat kondisi yang demikian, perlu diberikan solusi alternatif untuk membantu siswa dalam menguasai hiragana agar segala permasalahan dan kendala yang terdapat pada siswa dapat teratasi. Sehingga diperlukan suatu media pembelajaran yang memudahkan siswa untuk menguasai huruf. Dengan demikian, penulis memilih media kartu kuartet sebagai solusi alternatif, untuk mengatasi kendala dan permasalahan yang terdapat pada siswa agar dapat menguasai hiragana.

Media adalah segala sesuatu yang dapat digunakan untuk menyalurkan pesan dari pengirim ke penerima sehingga dapat merangsang pikiran, perasaan, perhatian, dan minat serta perhatian siswa sedemikian rupa sehingga proses belajar terjadi (Sadiman dkk, 2014:7). Dalam hal ini, penulis akan menggunakan salah satu media yaitu media visual yang berupa kartu kuartet. Kartu kuartet adalah sejenis permainan yang terdiri atas beberapa jumlah kartu bergambar. Pada setiap kartu kuartet tertera keterangan berupa tulisan yang menerangkan gambar yang ada di dalam setiap kartu. Sehubungan dengan hal di atas, media kartu kuartet diperkirakan mampu menyelesaikan masalah yang berkaitan dengan penguasaan Hiragana oleh siswa. Dalam hal ini, pembelajaran disampaikan dengan bantuan kartu kuartet dengan mengajak siswa bermain. Melalui bantuan kartu kuartet ini diharapkan pembelajaran akan menjadi lebih efektif dan efesien karena kartu kuartet memiliki banyak keunggulan seperti mengoptimalkan penyajian bahan ajar, menjadikan pembelajaran lebih menarik, dan menjadikan penerimaan pesan secara lebih merata.

\section{METODE PENELITIAN}

Jenis penelitian ini adalah penelitian kuantitatif. Arikunto (2016:27) yang mengemukakan penelitian kuantitatif adalah penelitian yang menggunakan angka, dimulai dari pengumpulan data, kemudian penafsiran data, dan terakhir ditampilkan hasilnya. Metode ini disebut metode kuantitatif karena data yang penelitian berupa angka-angka dan analisis menggunakan statistik, Sugiyono (2015:13). Metode yang akan digunakan dalam penelitian ini adalah metode eksperimen. Riduwan (2015:50) mengemukakan bahwa pendekatan eksperimen adalah suatu penelitian yang berusaha mencari pengaruh variabel tertentu terhadap variabel yang lain dalam kondisi yang terkontrol secara ketat. Jenis eksperimen penelitian ini adalah quasi 
experiment (eksperimen semu). Menurut Sugiyono (2013:114) eksperimen semu merupakan penelitian yang memiliki kelompok kontrol, tetapi tidak dapat berfungsi sepenuhnya untuk mengontrol variabel-variabel luar yang mempengaruhi pelaksanaan eksperimen. Desain yang akan digunakan dalam penelitian ini adalah Posttest Only Control Group Design, yaitu desain yang menggunakan sekelompok subjek penelitian dari suatu populasi tertentu, kemudian dikelompokkan menjadi dua kelompok kelas, yaitu kelas eksperimen dan kelas kontrol, (Arikunto, 2010:212).

Data dalam penelitian ini adalah skor hasil tes penguasaan hiragana siswa kelas X SMAN 6 Padang dengan menggunakan media kartu kuartet dan skor hasil tes penguasaan hiragana siswa kelas X SMAN 6 Padang tanpa menggunakan media kartu kuartet.

Instrumen yang akan digunakan untuk mengumpulkan data dalam penelitian ini adalah tes, yaitu tes penguasaan hiragana. Sesuai yang dikatakan Arikunto (2016:193), tes merupakan sederetan pertanyaan, atau latihan untuk mengukur keterampilan, pengetahuan, atau bakat yang dimiliki oleh individu atau kelompok. Dalam hal ini, pembelajaran hiragana dengan media kartu kuartet.

Adapun teknik pengumpulan data sebagai berikut. Pertama, pelaksanaan posttest. Kedua, pemeriksaan dan pemberian skor, memeriksa hasil penguasaan hiragana siswa berdasarkan kriteria atau rubrik yang sudah ditentukan. Ketiga, mengolah skor menjadi nilai yang menggunakan rumus persentase. Kemudian dilanjutkan dengan menganalisis data dengan langkah sebagai berikut. Pertama, menentukan nilai rata-rata hitung penguasaan hiragana siswa kelas X SMAN 6 Padang. Kedua, sebaran data. Ketiga, mengklasifikasikan hasil penguasaan hiragana siswa dengan dan tanpa menggunakan media kartu kuartet berdasarkan konversi skala 10. Keempat, mengklasifikasikan data berdasarkan indikator. Kelima, sebelum menguji persyaratan hipotesis terlebih dahulu dilakukan uji normalitas dan uji homogenitas. Keenam, melakukan pengujian hipotesis untuk mengetahui pengaruh media kartu kuartet terhadap penguasaan hiragana siswa kelas X SMA Negeri 6 Padang. Ketujuh, membuat pembahasan. Kedelapan, membuat kesimpulan hasil penelitian

\section{HASIL DAN PEMBAHASAN Temuan penelitian}

Berdasarkan analisis terhadap skor tes penguasaan hiragana diikuti oleh 36 orang siswa kelas eksperimen dan 33 orang siswa kelas kontrol. Pada kedua kelas sampel ini dilakukan perhitungan rata-rata, dan simpangan baku. Hasil perhitungan dapat dilihat pada tabel di bawah ini. :

Tabel 1 Penguasaan Hiragana Siswa Kelas Kontrol

\begin{tabular}{|l|l|l|}
\hline No & Kategori & Nilai \\
\hline 1 & Nilai Tertinggi & 93 \\
\hline 2 & Nilai Terendah & 15 \\
\hline 3 & Rata-rata & 65,82 \\
\hline 4 & Standar Deviasi & 21,37 \\
\hline
\end{tabular}


Tabel 2 Penguasaan Hiragana Siswa Kelas Eksperimen

\begin{tabular}{|l|l|l|}
\hline No & Kategori & Nilai \\
\hline 1 & Nilai Tertinggi & 100 \\
\hline 2 & Nilai Terendah & 35 \\
\hline 3 & Rata-rata & 81,72 \\
\hline 4 & Standar Deviasi & 17,25 \\
\hline
\end{tabular}

Berdasarkan tabel di atas, dapat dilihat nilai rata-rata siswa pada kelas eksperimen lebih tinggi dari nilai rata-rata siswa pada kelas kontrol. Dan simpangan baku kelas eksperimen lebih kecil dari simpangan baku kelas kontrol.

Hal ini menunjukkan bahwa nilai tes akhir kelas eksperimen lebih relatif sama dan mendekati rata-rata dibandingkan kelas kontrol yang lebih beragam. Untuk menjawab hipotesis penelitian yang menyatakan bahwa ada atau tidaknya pengaruh penggunaan kartu kuartet terhadap penguasaan hiragana Siswa Kelas X SMAN 6 Padang diketahui dengan cara membandingan penguasaan hiragana dengan menggunakan kartu kuartet dan tanpa menggunakan kartu kuartet. Untuk lebih jelasnya, perbandingan tersebut dapat dilihat pada tabel berikut.

Tabel 3 Perbandingan Penguasaan Hiragana Siswa Kelas X SMAN 6 Padang Tanpa dan Dengan Menggunakan Kartu Kuartet

\begin{tabular}{|l|l|l|l|l|}
\hline No & Kelompok & N & $\sum X 1$ & Rata-Rata \\
\hline 1 & Eksperimen & 36 & 2942 & 81,72 \\
\hline 2 & Kontrol & 33 & 2172 & 65,82 \\
\hline
\end{tabular}

Berdasarkan tabel di atas, dapat dilakukan uji-t untuk mengetahui Pengaruh kartu kuartet terhadap penguasaan hiragana siswa kelas X SMAN 6 Padang. Sebelum dilakukan uji-t terlebih dahulu dilakukan uji normalitas dan uji homogenitas sebagai berikut.

Tabel 4 Uji Normalitas

\begin{tabular}{|l|l|l|l|l|l|l|}
\hline No & Kelompok & N & Taraf Nyata & L0 & Lt & Distribusi \\
\hline 1 & Eksperimen & 36 & 0,05 & 0,1447 & 0,1476 & Normal \\
\hline 2 & Kontrol & 33 & 0,05 & 0,1467 & 0,154 & Normal \\
\hline
\end{tabular}

Berdasarkan tabel di atas, dapat disimpulkan bahwa (1) data berdistribusi normal pada taraf signifikan 0,05 untuk $\mathrm{n}=36$ setelah diberi perlakuan menggunakan kartu kuartet yaitu L0 kecil dari Lt $(0,1447<0,1476)$. (2) data berdistribusi normal pada taraf signifikan 0,05 untuk $\mathrm{n}=33$ tanpa diberi perlakuan menggunakan kartu kuartet yaitu L0 kecil dari Lt $(0,1467<0,154)$. 
Tabel 4 Uji Homgenitas

\begin{tabular}{|l|l|l|l|l|l|l|}
\hline No & Kelompok & $\mathrm{N}$ & Taraf Nyata & Fhitung & Ftabel & Keterangan \\
\hline 1 & Eksperimen & 36 & 0,05 & 1,53 & 1,53 & Homogen \\
\hline 2 & Kontrol & 33 & 0,05 & & & Homogen \\
\hline
\end{tabular}

Berdasarkan tabel di atas, disimpulkan bahwa kelompok data memiliki varian yang homogen pada taraf signifikan 0,05 dengan $\mathrm{dk}=\mathrm{n}-1$ karena Fhitung kecil dari Ftabel $(1,53<1,82)$. Berdasarkan hasil uji-t, penguasaan hiragana siswa kelas $X$ SMAN 6 Padang tanpa menggunakan media kartu kuartet dan dengan menggunakan media kartu kuartet dengan melakukan uji-t. Jika dilihat dari thitung dengan ttabel taraf signifikan $0,05 \%$ adalah 2,00 dengan derajat kebebasan $\mathrm{dk}=\mathrm{n} 1+\mathrm{n} 2-2$. Hal ini berarti thitung $>$ ttabel $3,41>2,00$ ). Jadi, dapat disimpulkan bahwa hipotesis diterima karena thitung $>$ ttabel .

\section{Pembahasan}

Sebagaimana telah dideskripsikan, hasil analisis data menunjukkan secara keseluruhan nilai penguasaan Hiragana siswa kelas X SMAN 6 Padang tanpa menggunakan kartu kuartet memiliki rata-rata 65,82 pada kualifikasi lebih dari cukup. Dalam penelitian ini, dapat diketahui penguasaan Hiragana siswa kelas X SMAN 6 Padang tanpa menggunakan kartu kuartet dari tiga indikator yang dinilai. Indikator tersebut adalah (1) mengidentifikasi penulisan dari hiragana ke romaji, (2) mengidentifikasi penulisan dari romaji ke hiragana. (3) menjodohkan hiragana dan romaji dengan benar Dalam penelitian ini diketahui tiga hal sebagai berikut.

Pertama, untuk indikator 1 (mengidentifikasi penulisan dari hiragana ke romaji) diperoleh rata-rat hitung sebesar $(60,69)$. Jika nilai rata-rata tersebut dibandingkan dengan KKM kelas X SMAN 6 Padang untuk bahasa Jepang adalah 75. Maka penguasaan hiragana belum memenuhi KKM. Nilai yang diperoleh kelas kontrol masih rendah dibandingkan dengan rata-rata kelas eksperimen.

Kedua, untuk indikator 2 (mengidentifikasi penulisan dari romaji ke hiragana) diperoleh rata-rata hitung sebesar $(60,09)$. Jika nilai rata-rata tersebut dibandingkan dengan KKM kelas X SMAN 6 Padang untuk bahasa Jepang adalah 75. Maka penguasaan hiragana belum memenuhi KKM. Nilai yang diperoleh kelas kontrol masih rendah dibandingkan dengan rata-rata kelas eksperimen.

Ketiga, untuk indikator 3 (menjodohkan hiragana dan romaji dengan benar) diperoleh rata-rata hitung sebesar $(80,60)$. Jika nilai rata-rata tersebut dibandingkan dengan KKM kelas X SMAN 6 Padang untuk bahasa Jepang adalah 75. Maka penguasaan hiragana sudah memenuhi KKM. Namun, nilai yang diperoleh kelas kontrol masih rendah dibandingkan dengan rata-rata kelas eksperimen.

Selanjutnya, penguasaan Hiragana siswa kelas X SMAN 6 Padang dengan menggunakan kartu kuartet memiliki rata-rata $(81,72)$ dengan klasifikasi baik dari tiga indikator yang dinilai. Indikator tersebut adalah (1) mengidentifikasi penulisan dari hiragana ke romaji, (2) mengidentifikasi penulisan dari romaji ke hiragana. (3) 
menjodohkan hiragana dan romaji dengan benar. Dalam penelitian ini diketahui tiga hal sebagai berikut.

Pertama, untuk indikator 1 (mengidentifikasi penulisan dari hiragana ke romaji) diperoleh rata-rat hitung sebesar $(76,66)$. Jika nilai rata-rata tersebut dibandingkan dengan KKM kelas X SMAN 6 Padang untuk bahasa Jepang adalah 75. Maka penguasaan hiragana sudah memenuhi KKM.

Kedua, untuk indikator 2 (mengidentifikasi penulisan dari romaji ke hiragana) diperoleh rata-rata hitung sebesar $(80,13)$. Jika nilai rata-rata tersebut dibandingkan dengan KKM kelas X SMAN 6 Padang untuk bahasa Jepang adalah 75. Maka penguasaan hiragana sudah memenuhi KKM

Ketiga, untuk indikator 3 (menjodohkan hiragana dan romaji dengan benar) diperoleh rata-rata hitung sebesar $(95,83)$. Jika nilai rata-rata tersebut dibandingkan dengan KKM kelas X SMAN 6 Padang untuk bahasa Jepang adalah 75. Maka penguasaan hiragana sudah memenuhi KKM.

Jika dibandingkan antara nilai rata-rata kelas kontrol dengan kelas eksperimen perindikator terlihat perbedaan yang signifikan. Hal ini disebabkan pada saat pelaksanaan pembelajaran di kelas ekperimen menggunakan kartu kuartet untuk membantu siswa lebih aktif dan antusias untuk membaca kosakata yang terdapat di dalam setiap kartu. Semua kosakata ditulis menggunakan huruf hiragana. Kemudian, siswa diminta untuk dapat mengklasifikasikan hiragana berdasarkan teori bunyi yang telah di jelaskan di awal pertemuan.

Perbedaan rata-rata penguasaan hiragana pada siswa kelas X SMA Negeri 6 Padang tanpa dan dengan menggunakan media kartu kuartet, dianggap sebagai pengaruh yang ditimbulkan oleh penggunaan media kartu kuartet yang diberikan pada siswa kelas X SMA Negeri 6 Padang. Dengan demikian, disimpulkan bahwa penggunaan media kartu kuartet berpengaruh secara signifikan terhadap penguasaan hiragana pada siswa kelas X SMA Negeri 6 Padang.

Kemudian, jika dibandingkan dengan penelitian terdahulu mengenai penggunaan kartu kuartet, dilihat dari penelitian yang dilakukan oleh Zulfikar dan Laelah Azizah (2017) yang meneliti tentang Keefektifitasan Penggunaan Media Pembelajaran Kartu Kuartet dalam Pembelajaran Keterampilan Berbicara Bahasa Jerman Siswa Kelas XI MA Negeri 1 Makassar. Dalam penelitiannya, Zulfikar dan Laelah Azizah menyimpulkan bahwa penggunaan media pembelajaran kartu kuartet efektif dalam pembelajaran keterampilan berbicara bahasa Jerman siswa kelas XI MIPA MA Negeri 1 Makassar. Perolehan nilai post-test siswa, pada kelas eksperimen nilai terendah yaitu 50 dan nilai tertinggi 91 dengan nilai ratarata 69,8, sedangkan pada kelas kontrol diperoleh nilai 8 untuk nilai terendah dan 67 untuk nilai tertinggi dengan nilai ratarata 38,1 . Dalam penelitian ini, penggunaan kartu kuartet juga berpengaruh terhadap penguasaan hiragana siswa kelas X SMAN 6 Padang. Perolehan nilai post-test siswa, pada kelas eksperimen nilai terendah yaitu 35 dan nilai tertinggi 100 dengan nilai ratarata 81,72, sedangkan pada kelas kontrol diperoleh nilai 15 untuk nilai terendah dan 93 untuk nilai tertinggi dengan nilai ratarata 65,82. Dengan demikian, dapat disimpulkan bahwa penggunaan media kartu kuartet tidak hanya efektif dan memberikan peningkatan yang signifikan terhadap kemampuan bebicara Bahasa Jerman saja, namun juga efektif dan memberikan peningkatan yang signifikan terhadap penguasaan hiragana bahasa Jepang. Selain itu, 
sesuai dengan salah satu dari tujuan media kartu kuartet yaitu, kartu kuartet dapat memudahkan peserta didik dalam mengingat dan mengimajinasikan kata-kata yang ada didalam kartu kuartet karena dilengkapi dengan gambar. Pada penelitian ini, kartu kuartet dirancang dengan menuliskan setiap kosakata dengan menggunakan hiragana serta dilengkapi dengan gambar agar siswa dapat memahami dan mengingat arti dari setiap kosakata yang disediakan

\section{KESIMPULAN}

Berdasarkan hasil analisis data penelitian yang telah dilakukan, dapat disimpulkan tiga hal berikut;

1. Pertama, penguasaan hiragana siswa kelas X SMA Negeri 6 Padang tanpa menggunakan media kartu kuartet berada pada kualifkasi cukup $(65,82)$.

2. penguasaan hiragana siswa kelas X SMA Negeri 6 Padang dengan menggunakan media kartu kuartet berada pada kualifkasi baik $(81,72)$.

3. Berdasarkan hasil uji-t disimpukan bahwa terdapat pengaruh yang signifikan dari penggunaan media kartu kuartet terhadap penguasaan hiragana siswa kelas X SMA Negeri 6 Padang karena thitung besar dari ttabel $(3,41>2,00)$. Jadi dapat disimpukan bahwa penguasaan hiragana siswa kelas X SMA Negeri 6 Padang denngan diberi perlakuan menggunakan media kartu kuartet lebih baik dari pada tanpa menggunakan media kartu kuartet

\section{REFERENSI}

Adriyanto, Refnaldi, Yulia Nova. 2018. "Dampak Metode Cooperative Learning Tipe Teams Games Tournament Terhadap Penguasaan Hiragana Siswa Kelas X Ipa 2 Dan Ipa 3 Sma Kartika 1-5 Padang": Jurnal Prodi Pendidikan Bahasa Jepang Universitas Negeri Padang.

Arikunto, Suharsimi. 2016. Prosedur Penelitian Suatu Pendekatan Praktik. Jakarta: PT Rineka Cipta.

Rahmi, Ulfia, Aneos Noviyanti, dan Dewi J Melia. 2016. Efektivitas Metode Card Sort Terhadap Kemampuan Mengingat Huruf Hiragana Dalam Bahasa Jepang.(Online)(http://ejournal.upi.edu/index.php/japanedu/article/view/38 37/2735). Diakses pada 25 Maret 2019

Riduwan. 2015. Belajar Mudah Penelitian untuk Guru - Karyawan dan Peneliti Pemula. Bandung: Alfabeta.

Sadiman, Arief S., Rahardjo, Haryono Anung, \& Harjito. 2014. Media pendidikan.Jakarta:PT Raja Grafindo Persada.

Sugiyono. 2013. Metode Penelitian dan Pendidikan. Bandung: Alfabeta. Sugiyono. 2015. Metode Penelitian dan Pengembangan(Research and Development/R\&D). Bandung: Alfabeta. 
Sugiyono. 2014. Statstika untuk Penelitian. Bandung: Alfabeta. Sutedi, Dedi. 2009. Penelitian Pendidikan Bahasa Jepang. Bandung: Humaniora Utama Press.

Sutedi, Dedi. 2011. Penelitian Pendidikan Bahasa Jepang. Bandung: UPI Press.

Yuana, Cuk. 2012. Nihongo Yasashii SMA Kelas X. Surabaya: Yudhistira.

Zulfikar dan Azizah, Laelah. 2017. "Keefektifan Penggunaan Media Pembelajaran Kartu Kuartet dalam Pembelajaran Keterampilan Berbicara Bahasa Jerman Siswa Kelas XI MA Negeri 1 Makassar" (Online) (ojs.unm.ac.id/eralingua/article/view/4412) diakses pada 24 Oktober 2018 